\title{
Journal of the Medical Sciences
}

(Berkala Ilmu Kedokteran)

Volume 53, Number 4, 2021; 398-407

http://dx.doi.org/10.19106/JMedSci005304202109

\section{Treatment of functioning pituitary macroadenoma with endoscopic transsphenoidal surgery: a case report}

\author{
Agusni $^{1}$, Willy Adhimarta ${ }^{23}$, Andi Asadul Islam ${ }^{2,3}$, Djoko Widodo ${ }^{2,3}$, Nasrullah ${ }^{2,3}$, Andi \\ Ihwan $^{2,3}$, Prihantono ${ }^{1}$, Muhammad Faruk ${ }^{1}$ \\ ${ }^{1}$ Department of Surgery, Faculty of Medicine, Universitas Hasanuddin, Makassar, ${ }^{2}$ Division of \\ Neurosurgery, Department of Surgery, Faculty of Medicine, Universitas Hasanuddin, Makassar, \\ ${ }^{3}$ Division of Neurosurgery, Department of Surgery, DR. Wahidin Sudirohusodo Hospital, \\ Makassar, Indonesia
}

Submited: 2020-09-09

Accepted : 2020-11-14

Keywords:

endoscopic transsphenoidal surgery

pituitary macroadenoma

pituitary tumor

acromegaly

amenorrhea; sella turcica

\begin{abstract}
Pituitary macroadenomas are benign tumors in the pituitary gland measuring more than $1 \mathrm{~cm}$ in diameter. Pituitary macroadenomas account for 8 to $10 \%$ of all intracranial tumors and occur primarily in the anterior pituitary lobe and rarely in the posterior lobe. Most pituitary macroadenomas are non-functioning tumors, which show clinical symptoms due to tumor pressure and do not increase hormonal activity. In this case, a 40 y.o. woman was diagnosed with a pituitary macroadenoma after showing clinical symptoms of a functioning tumor, namely acromegaly, prognathism, and large, beefy hands and feet, for the past 4 years. Complaints were accompanied by amenorrhea, intermittent cephalgia, and hemianopsia in the right eye. Blood laboratory tests revealed increased levels of prolactin and growth hormone, while the results of computed tomography (CT) scans and magnetic resonance imaging (MRI) of the head indicate the presence of a pituitary macroadenoma. Endoscopic transsphenoidal surgery, a minimally invasive procedure, was performed with minimal complications.
\end{abstract}




\section{INTRODUCTION}

Pituitary adenomas are benign tumors originating from cells in the pituitary gland that ultimately fill sellar and suprasellar spaces..$^{1-3}$ Such tumors are categorized as functioning if they increase the pituitary hormone production and vice versa. ${ }^{1,2}$ Depending upon their size, pituitary adenomas are classified as either microadenoma (i.e., $<1$ $\mathrm{cm}$ in diameter) or macroadenoma (i.e., $>1 \mathrm{~cm}$ in diameter). ${ }^{4}$ Accounting for 8 to $10 \%$ of all intracranial tumors, pituitary adenomas have a peak distribution at 35-45 years of age in a nearly equal ratio between the sexes. Pituitary adenomas occur primarily in the anterior pituitary lobe and rarely in the posterior lobe. ${ }^{4,5}$

Schloffer first successfully removed the pituitary gland by following a transsphenoidal approach in 1906, In 1912, Harvey Cushing modified the sublabial transsphenoidal approach by using a modified form of the Schloffer method in a patient with acromegaly. ${ }^{4,6}$ Decades later, endoscopyguided transsphenoidal surgery was standardized by Jho and Carrauin in 1997, and 2002, Cappabianca et al. ${ }^{6}$ introduced a method of enhancing the illumination and visualization of the tumor. ${ }^{7}$ At present, innovative sellar and parasellar surgical procedures are being implemented after endoscopy. ${ }^{4,6}$

We reported in this study a rare case of functioning pituitary macroadenoma and successful endoscopic transsphenoidal tumor endoscopy as a minimally invasive approach.

\section{CASE}

A 40-year-old woman presented with the chief complaint of having enlarged fingers and toes for the past 4 years, which she recognized due to the seemingly gradual narrowing of her shoes. The complaint was accompanied by intermittent headaches, also for the past 4 years but with increased frequency during the previous 2 months. The patient also reported increasingly blurred vision toward the center of her right eye and enlarged upper eyelids, despite no pain or redness in either eye. Her forehead and jaw had widened and begun to protrude. During the past 4 years, the patient had also never menstruated, whereas her previous menstrual pattern was once monthly for approximately 6 days each time. The patient also denied experiencing any decreased appetite or weight loss, weakness or fatigue, heart palpitations, or milky discharge from the nipples.

The patient married and with a daughter. There was no history of abortion, trauma, contraceptives use, recent drugs use, hypertension, diabetes mellitus, heart or kidney disorders, or surgery. She also denied any history of congenital disease, malignancy, or conditions resembling her current complaint.

The patient's physical examination revealed vital signs and nutritional status within the normal limits and no abnormalities in the neck, thorax, or abdomen. However, compared with previous 5 years image, the forehead was protruding, the nose and lips had widened, and mandibular prognathism. Interdental dilation and malocclusion could be observed. All fingers and toes on both hands and feet also became enlarged and beefy, even without edema. The clinical presentation of the patients is depicted in FIGURE 1.

An endocrinological examination in the laboratory revealed an increase in prolactin levels as much as $48.3 \mathrm{ng} /$ $\mathrm{mL}$ (normal value: 2.8-29.2 ng/mL) and growth hormone as much as 107.0 $\mathrm{ng} / \mathrm{mL}$ (normal value: $<8 \mathrm{ng} / \mathrm{mL}$ ). An ophthalmologist also performed a fundoscopy that revealed optic atrophy in the right eye (i.e., pallor of the optic nerve head), while a perimetric test demonstrated nasal hemianopsia in the right eye and nasal peripheral hemianopsia in the left eye (FIGURE 2). 


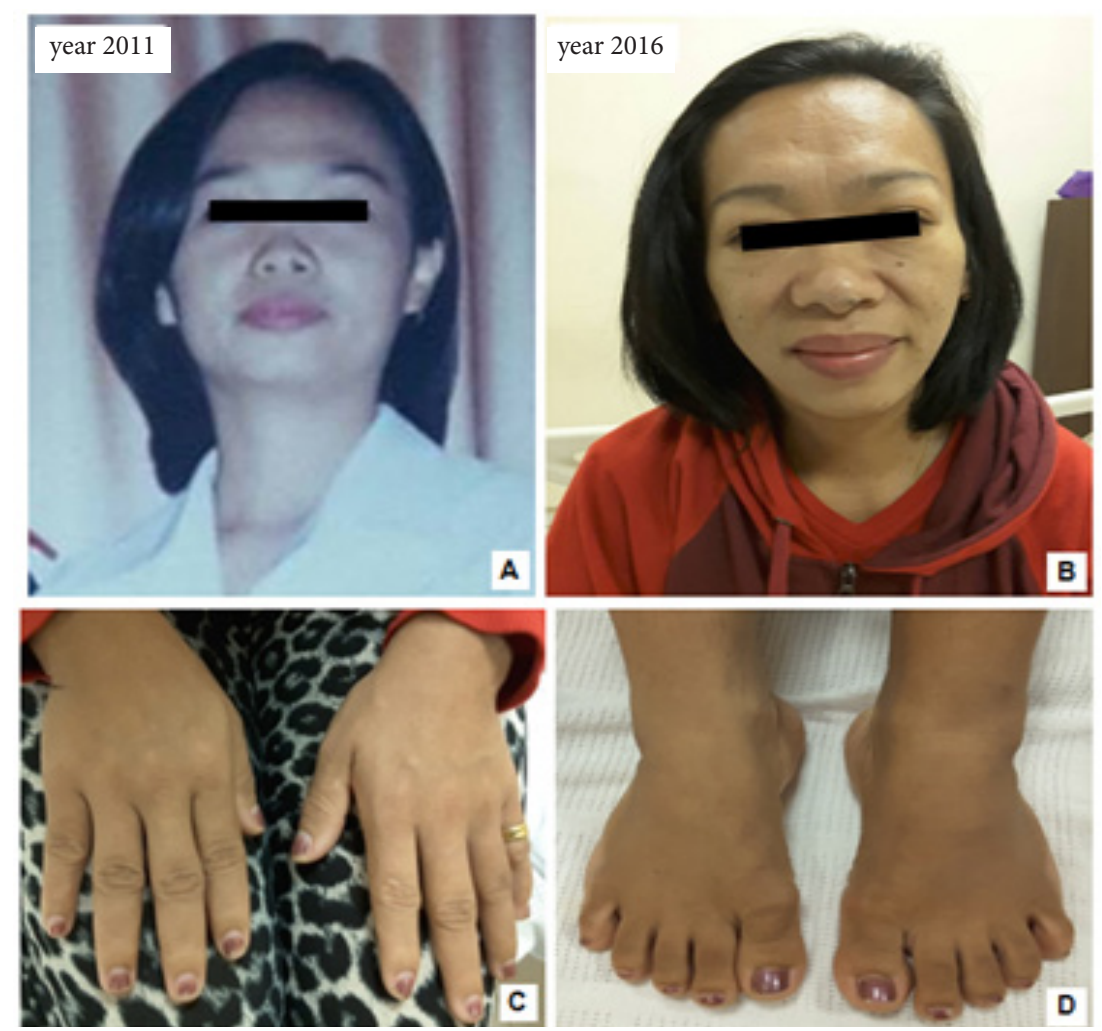

FIGURE1. Physical examination: A) Facial shape 5 years before being diagnosed with pituitary macroadenoma and B) when diagnosed with pituitary macroadenoma, along with large, beefy C) hands and D) feet.

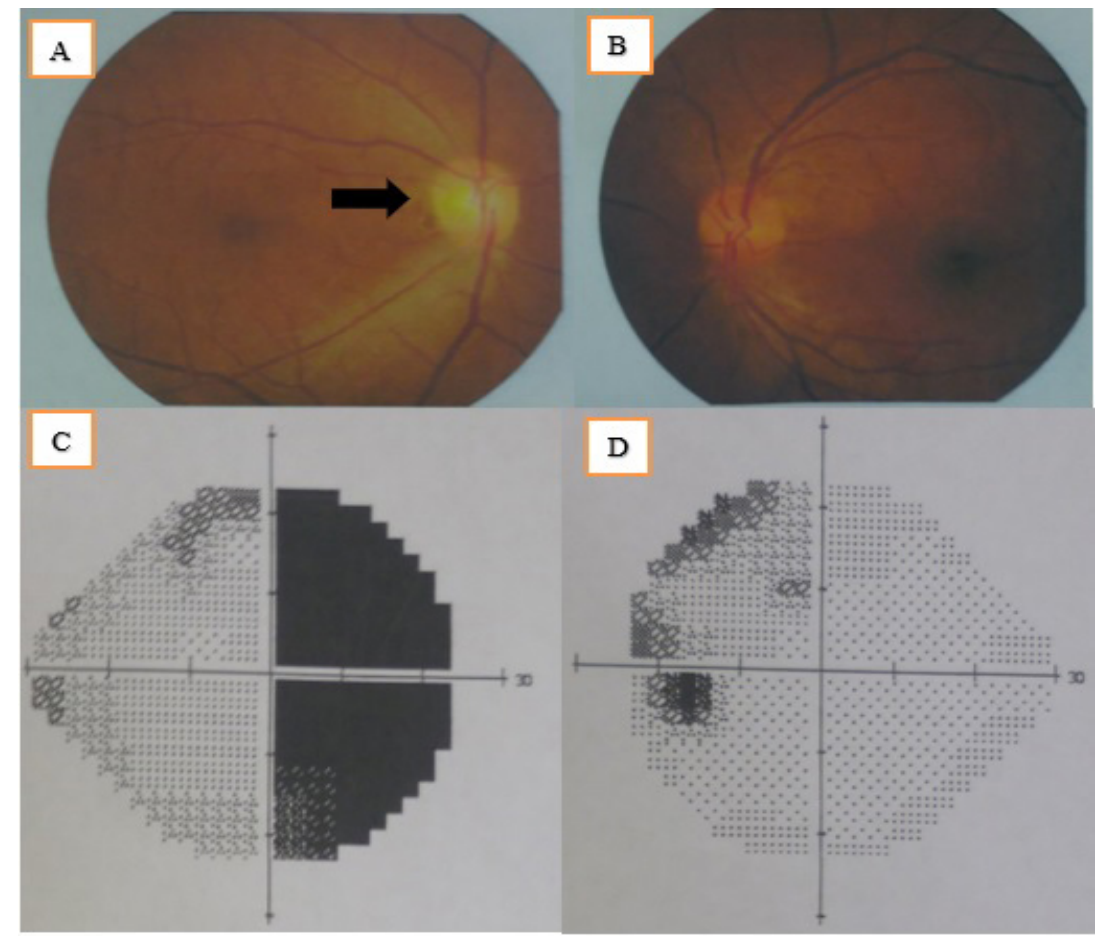

FIGURE 2. Funduscopic examination: A) Optic atrophy in the right eye (black arrow), B) normal funduscopy of the left eye, C) nasal hemianopsia in a perimetric image of the right eye, and D) defect of the nasal peripheral visual field inthe left eye. 
A computed tomography (CT) scan without contrast and magnetic resonance imaging (MRI) of the head shows a pituitary macroadenoma $33.4 \mathrm{~mm}$ long, $20.7 \mathrm{~mm}$ wide, and $28.7 \mathrm{~mm}$ deep extending upward and out of the sella turcica and, in the process, stretching the optic chiasm and optic nerves. The tumor distends the thin bone at the base of the sell turcica into the sphenoid sinus (FIGURE 3).

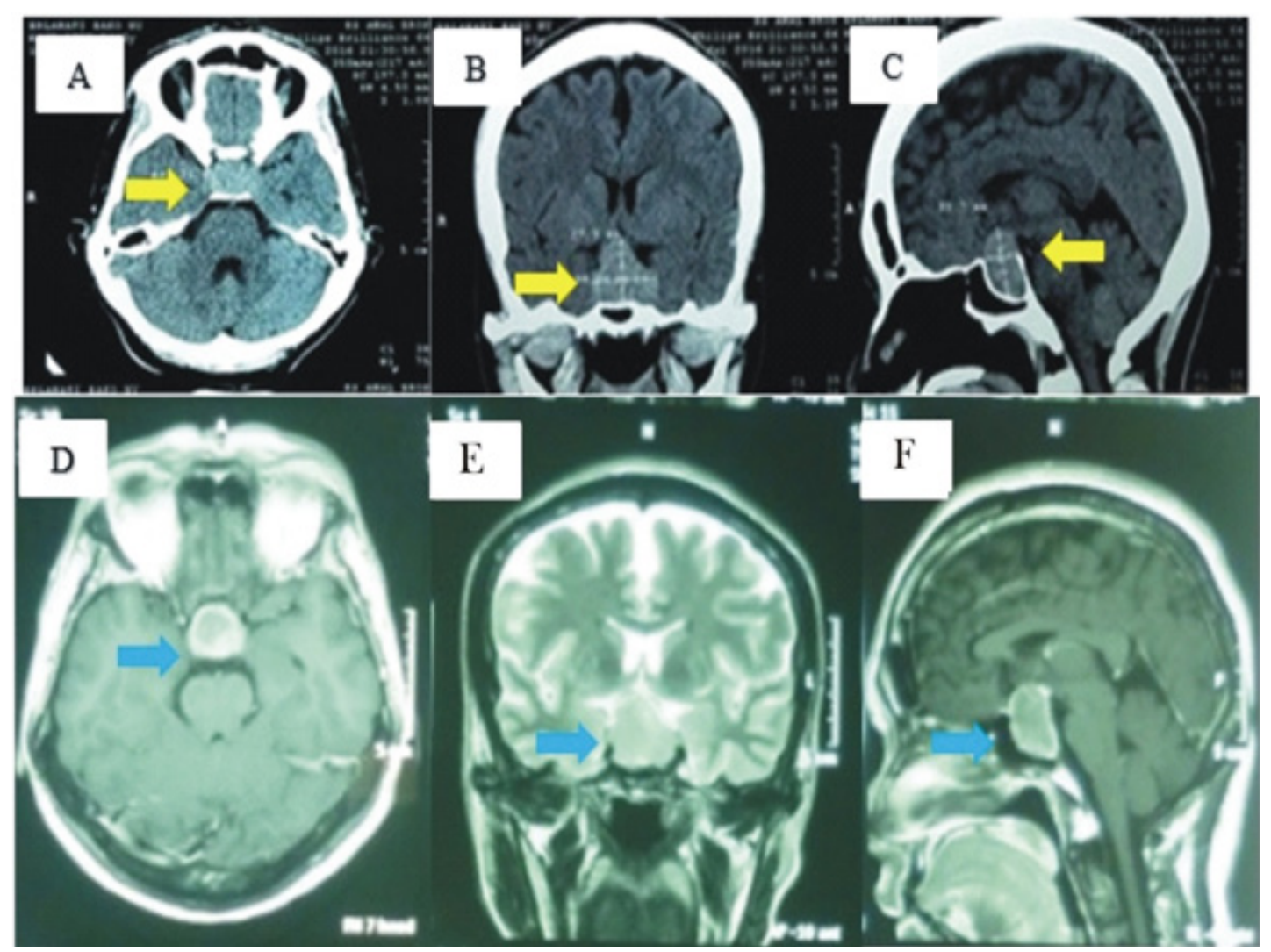

FIGURE 3. ACT scan of heads hows a slight hyperdense mass on the sella turcica in the (A) axial, (B) coronal, and (C) sagittal planes (yellow arrow), with a lobulated size of $33.4 \times 20.7 \times 28.7 \mathrm{~mm}$, which suggests a pituitary macroadenoma. An MRI of the head in the (D) axial, (E) coronal, and (F) sagittal planes (blue arrow) shows a contrasting suprasellar round, lobulated, well-defined isointense mass in the pituitary area, with mostly regular edges and measuring $33 \times 21 \times$ $34 \mathrm{~mm}$, which also suggests a pituitary macroadenoma.

Based on the patient's history, physical examination, and supporting examinations, the patient was diagnosed with a functioning pituitary macroadenoma, then the patient begins to be prepared for endoscopic transsphenoidal surgery to remove the tumor.

We performed endoscopic transsphenoidal surgery under general anesthesia. The patient was placed in the supine position on the operating table, with the back elevated at a $30^{\circ}$ angle and the head tilted back at a $20^{\circ}$ angle, rotated toward the left shoulder at a $25^{\circ}$ angle, and rigidly fixated.

The surgeon was positioned on the patient's right side. The abinostril approach start from the right nostril. A $0^{\circ}$ rigid endoscope $(180 / 4 \mathrm{~mm})$ was used without an endoscope holder, although a $45^{\circ}$ endoscope was also used occasionally. The endoscope was navigated into the nasal cavity until it 
reaches the sphenoid floor (FIGURE 4A), which is approximately $1 \mathrm{~cm}$ above the inferior margin of the middle turbinate. A rescue flap to prevent injury to the vascular pedicle of the posterior nasoseptal artery was raised on the right side, and the middle turbinate was resected. A large opening was made both in the posterior nasal septum and anterior wall of the sphenoidal sinus by using a high-speed drill with a diamond burr. Inside the sphenoidal sinus, the sell turcica and optic carotid recess were identified, and the anterior wall and floor of the sella turcica were opened with a drill (FIGURE 4B and 4C). Once the dura mater was opened (FIGURE 4D), the tumor was removed (FIGURE 4E and 4F).

To reconstruct the sella turcica region, we used a combination of fascia lata, abdominal fat, and fibrin glue. A vascularized nasal septal flap, namely a mucoperichondrial flap based on the posterior nasoseptal artery, was raised as a final layer over the only graft, followed by a Foley catheter as a buttress to prevent significant intraoperative cerebrospinal fluid (CSF) leakage.

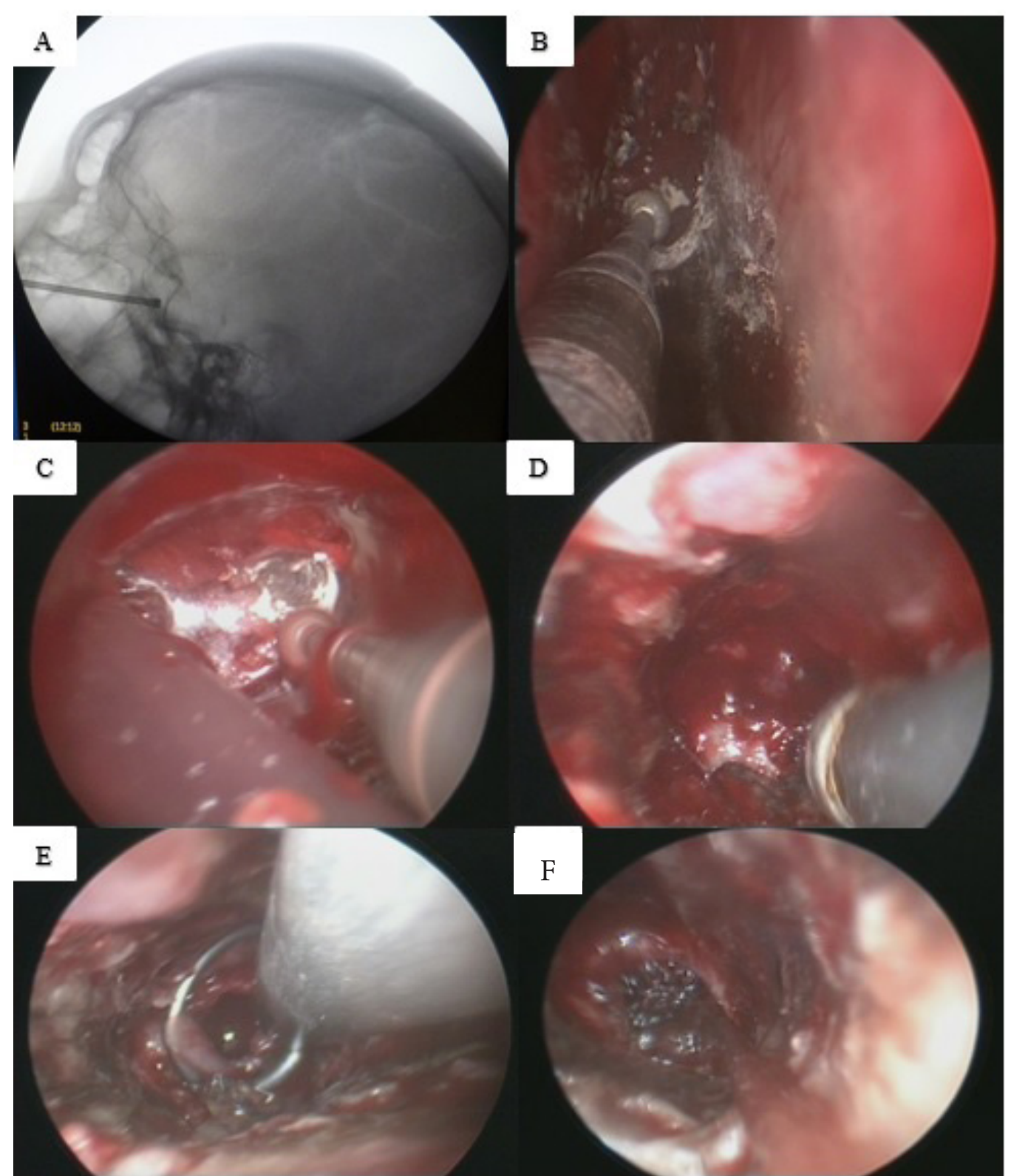

FIGURE 4. Endoscopic transsphenoidal procedure: A)Marking the area with a C-arm,B) drilling to open the sphenoid sinus,C) sella turcica,and D) dura mater, E) and F) identifying the tumor, followed by its removal. 
The patient was treated for 5 days after surgery. The patient was admitted to the outpatient unit after her condition was stable and no significant postoperative complications were observed. One week after surgery, the patient reported less frequent headaches than before surgery and there was a gradual improvement in the limited vision of the right eye. The fingers and hands and feet were no longer enlarged, visible from the loose shoes.

The results of a histopathological examination indicated that the tumor consisted of sheet-shaped cells between erythrocytes. The cells were atypical, monomorphic, and solid, with either round or ovoid nuclei. Mitotic cells were not detected in the tumor, so the conclusion from the histopathological examination was a benign pituitary adenoma.

Ten weeks after surgery, a perimetric examination (FIGURE 5), CT scan of the head with contrast (FIGURE 6), and endocrinological evaluation were conducted. Among the results, the level of prolactin had normalized to $4.3 \mathrm{ng} / \mathrm{mL}$ (normal value: $2.8-29.2 \mathrm{ng} / \mathrm{mL}$ ), while the level of growth hormone had dropped drastically to56.8 $\mathrm{ng} / \mathrm{mL}$ (normal value: $<8 \mathrm{ng} / \mathrm{mL}$ ). It recommended for ongoing recurrence screening including annual CT scans and MRI monitoring.

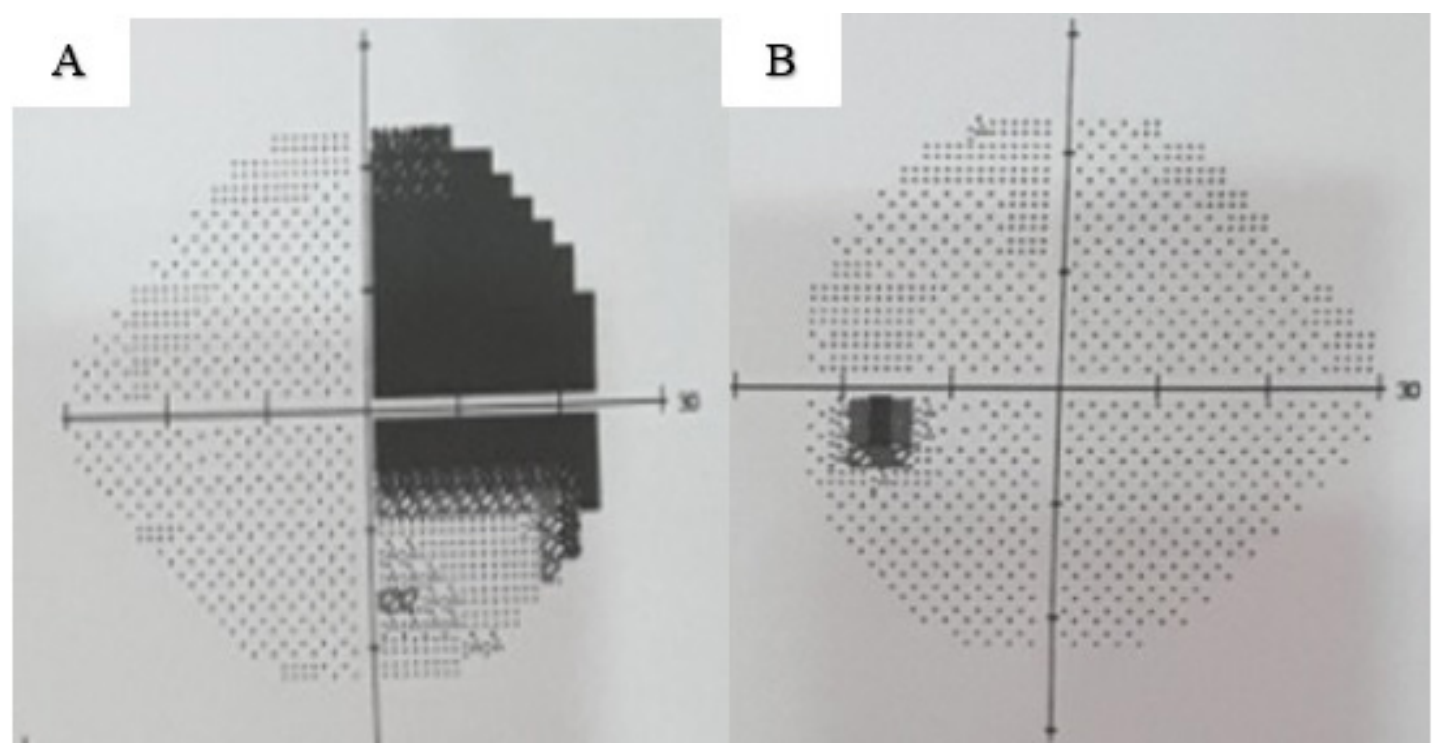

FIGURE 5. Results of a postsurgical perimetric examination: A) Nasal hemianopsia with improvement in the right eye and B) normal status in the left eye.

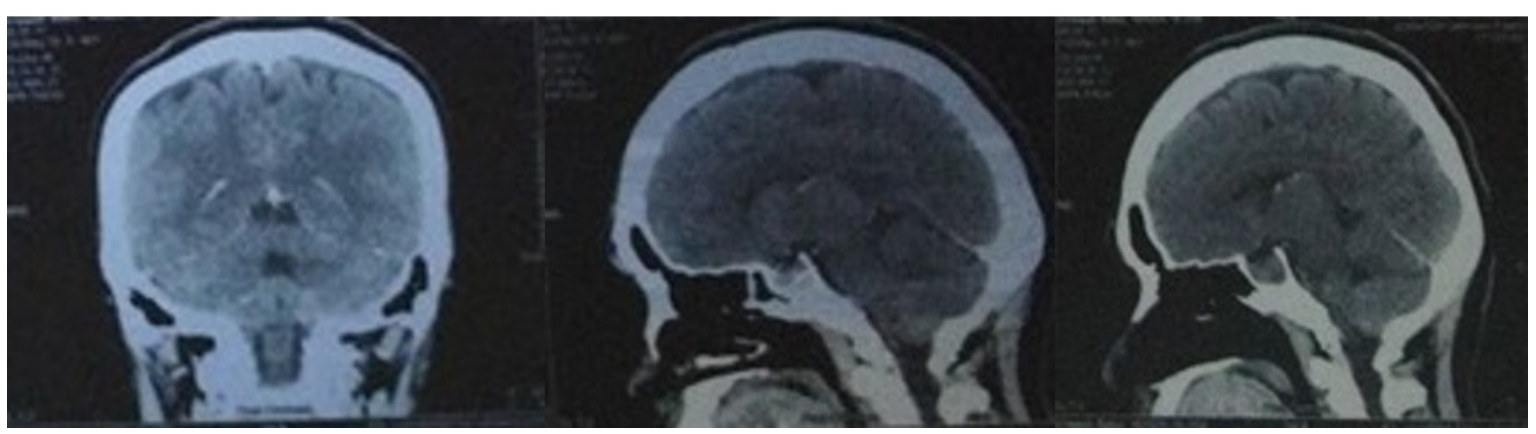

FIGURE 6. A CT scan of head with contrast shows no hyperdense lesions on the sella turcica and no hyper-or hypodense intracerebral lesions. 


\section{DISCUSSION}

The pituitary gland regulates the function of the thyroid gland, adrenal glands, ovaries, and testes, as well as controls lactation, uterine contractions during childbirth, linear growth, and the development and regulation of the osmolality and volume of intravascular fluid, namely by maintaining fluid absorption in the kidneys. ${ }^{8}$ The presence of a tumor in the pituitary gland disrupts hormone production, suppresses structures around the mass, and hinders blood supply to the gland. ${ }^{9,10}$

In terms of hormonal function, 85 to $90 \%$ of pituitary tumors are functioning tumors, whereas only 10 to $15 \%$ are nonfunctioning. ${ }^{10-12}$ Functioning adenomas usually appear earlier than nonfunctioning adenomas due to the effects of the hormones produced. By contrast, non-functioning adenomas, which are usually larger, exert a tumor-suppressive effect in the form of symptoms such as headaches, visual field defects, cranial nerve deficits, panhypopituitarism, and pituitary apoplexy. ${ }^{8,10,12}$

Patients with pituitary macroadenoma may be asymptomatic or else present with complaints caused by hormonal imbalance or tumor-inducing effects. Pituitary disorders have various clinical signs depending on the type, size, and progression of the tumors. Pituitary adenomas often indicate disorders caused by the hypo- or hyperfunction of the anterior pituitary hormones.,13 In our case, the patient presented with symptoms of acromegaly, including enlarged fingers and toes on both hands and feet, along with a widened and protruding forehead and jaw, enlarged nose and lips, prognathous jaw, and mild malocclusion for the past 4 years.

In general, hormonal effects depend on the type of hormone involved, especially according to the size and mass effect of the tumor and the hormonal abnormalities. ${ }^{12,14}$ The anterior pituitary cells are not as susceptible to tumorinducing effects as prolactin and somatotropin, whereas corticotrophin and thyrotropin are more resistant. ${ }^{4}$ In premenopausal women, possible clinical features include irregular menstruation and amenorrhea, ${ }^{4,8}$ as in our case, in which the patient had amenorrhea for 4 years despite previously having a regular menstrual pattern every month. Amenorrhea in the patient occurred due to hyperprolactinemia, as evidenced by increased prolactin levels in the laboratory results. Hyperprolactinemia is a pituitary disorder that can cause amenorrhea, related to its effect on GnRH and estrogen deficiency.

Another clinical feature of macroadenoma relates primarily to the suppressive effect of the tumor on the surrounding structures, which in the sella turcica most often causes visual disturbances and headaches. ${ }^{10,14}$ In particular, impaired vision is caused by the compression of the optic nerve structures, due to which the lateral spread compresses the cavernous sinuses, thereby resulting in ophthalmoplegia, diplopia, and/or ptosis. ${ }^{4,10}$ In our case, the patient had a headache and a limited field of view in the right eye, which indicated that the tumor was in the sella turcica.

Such diagnoses are usually justified by the patient's history and results of various physical examinations but nevertheless need confirmation by radiological and laboratory examinations. CT scans are quite specific and can detect tumors according to their calcification, whereas MRI can provide a clearer image of soft tissue structures and blood vessels. Beyond that, the high resolution allows MRI to recognize small lesions and can show their relationships with surrounding structures. ${ }^{1}$ In our case, a CT scan was performed with the results of a pituitary macroadenoma, which along with an MRI examination indicated a pituitary macroadenoma. 
Various studies have shown that 85 to $90 \%$ of all pituitary tumors are functioning tumors and mostly microadenoma. ${ }^{5,10,15}$ imaging diagnosis, hormonal status, surgical, radiotherapeutic, and pharmacological treatment, and outcome. Results . 485 patients $(54 \%$ men, mean age $53 \pm 14$ years Other research has indicated that most cases of pituitary macroadenoma involve non-functioning tumors, which cause clinical symptoms due to pressing the surrounding structures but do not increase hormonal activity. ${ }^{16}$ Our case showed the functioning pituitary macroadenoma was also characterized by increased levels of growth hormone and prolactin. Histopathological examination proved useful for categorizing tumor types, including in terms of aggressiveness, presence or absence of dura mater invasion, degree of granulation, and/or atypical appearance of cells. ${ }^{17}$ Histopathological examination results of our case ultimately confirmed a benign pituitary adenoma without any mitosis.

Managing a pituitary adenoma should prioritize decompressing the nervous system and restoring the normal secretion of hormones. To those ends, three basic therapeutic modalities that can be applied are operative therapy, radiation therapy, and therapy with drugs. ${ }^{6,7,10,18}$ In the past two decades, endoscopic transsphenoidal surgery has been widely used in the surgical management of pituitary adenomas. Zhou et al. ${ }^{6}$ reported on 1,166 transsphenoidal endoscopic surgeries which reduced injury to the nasal cavity while executing the microsurgical approach and also provided better vision. The endoscopic transsphenoidal resection method of pituitary adenomas is more effective and safer than traditional microscopic approaches. ${ }^{6,7,18}$ The endoscopic transsphenoidal approach provides panoramic vision within the surgical area, a better working angle, and minimal injury to the nasal cavity area. ${ }^{16}$

Reporting from Belgium, D’Haens et $a .^{19}$ found that the incidence of complications (i.e., CSF leakage) for most patients after endoscopic transsphenoidal surgery was $10 \% .^{20}$ Goudakos et al..$^{21}$ demonstrated that rates of gross tumor removal and CSF leakage were similar between groups who received endoscopic versus microscopic transsphenoidal pituitary surgery. However, that same study revealed a lower incidence of postoperative diabetes insipidus and shorter hospital stays among patients in the endoscopic groups. ${ }^{21}$ Another systematic review by Razak et al. $^{20}$ in the United Kingdom also observed the efficacy of transsphenoidal surgery and its capacity to reduce the need for craniotomy, even when the tumor volume appears large in preoperative imaging studies.

\section{CONCLUSION}

Functioning pituitary macroadenoma is a rare case of benign intracranial tumor, with symptoms that arise due to tumor pressing and increased hormone levels. Minimally invasive procedures such as endoscopic transsphenoidal surgery can assure minimal complications.

\section{ACKNOWLEDGEMENTS}

We would like to thanks the patient who gives the researchers team permission of using her case as report study.

\section{REFERENCES}

1. Penar PL, Nathan DJ, Nathan $\mathrm{MH}$, Salsali A. Pituitary tumor diagnosis and treatment. Curr Neurol Neurosci Rep 2002; 2(3):236-45.

https://doi.org/10.1007/s11910-002-0082-6

2. Theodros D, Patel M, Ruzevick J, Lim M, Bettegowda C. Pituitary 
adenomas: historical perspective, surgical management and future directions. CNS Oncol 2015; 4(6):411-29. https:/doi.org/10.2217/cns.15.21

3. Adriani JR, Mustamir N, Prihantono P, Faruk M. Pituitary tumor: presentation, diagnosis, and management using the transsphenoidal endoscopy. Int J Med Rev Case Rep 2020; 4(4):50-5. https://doi.org/10.5455/IJMRCR. pituitary-tumour-management-dx

4. Jane JAJ, Laws ERJ. The surgical management of pituitary adenomas in a series of 3,093 patients. J Am Coll Surg 2001; 193(6):651-9.

https://doi.org/10.1016/s10727515(01)01101-2

5. McDowell BD, Wallace RB, Carnahan RM, Chrischilles EA, Lynch CF, Schlechte JA. Demographic differences in incidence for pituitary adenoma. Pituitary 2011; 14(1):23-30. https://doi.org/10.1007/s11102-010-0253-4

6. Wang $\mathrm{F}$, Zhou $\mathrm{T}$, Wei S, Meng X, Zhang J, Hou Y, et al. Endoscopic endonasal transsphenoidal surgery of 1,166 pituitary adenomas. Surg Endosc 2015; 29(6):1270-80. https://doi.org/10.1007/s00464-014-3815-0

7. Cappabianca P, Cavallo LM, Colao A, Del Basso De Caro M, Esposito F, Cirillo S, et al. Endoscopic endonasal transsphenoidal approach: outcome analysis of 100 consecutive procedures. Minim Invasive Neurosurg 2002; 45(4):193-200. https://doi.org/10.1055/s-2002-36197

8. Gibbs IC, Tuniz F, Laws ER, Katznelson L. Pituitary Tumors. In: Hoppe RT, Phillips TL, Roach MBT-L and PT of RO (Third E, editors. Leibel and Phillips Textbook of Radiation Oncology. Third Edit. Philadelphia: W.B. Saunders; 2010. p. 477-86.

9. Levy A. Pituitary disease: presentation, diagnosis, and management. J Neurol Neurosurg Psychiatry2004;75(suppl_3):iii47-52. https://doi.org/10.1136/jnnp.2004.045740
10. Stacey RJ, Powell MP. Sellar and Parasellar Tumors. In: Moore AJ, Newell DW, editors. Neurosurgery: Principles and Practice. London: Springer London; 2005. p.187-204. https://doi.org/10.1007/1-84628-051-6_11

11. Nomikos P, Ladar C, Fahlbusch R, Buchfelder M. Impact of primary surgery on pituitary function in patients with non-functioning pituitary adenomas? A study on 721 patients. Acta Neurochir (Wien) 2004; 146(1):27-35. https://doi.org/10.1007/s00701-003-0174-3

12. Suh JH, Chao ST, Weil RJ. Pituitary Tumors. In: Gunderson LL, Tepper JEBT-CRO (Third E, editors. Clinical Radiation Oncology. $3^{\text {rd }}$ Edit. Philadelphia: W.B. Saunders; 2012. p.493-509. https://www. sciencedirect.com/science/article/ pii/B9781437716375000274

13. Abu Dabrh AM, Mohammed K, Asi N, Farah WH, Wang Z, Farah MH, et al. Surgical interventions and medical treatments in treatment-naïve patients with acromegaly: systematic review and meta-analysis. J Clin Endocrinol Metab 2014; 99(11):400314.

https://doi.org/10.1210/jc.2014-2900

14. Blevins LS. Pituitary Tumors. In: Aminoff MJ, Daroff RBBT-E of the NS (Second E, editors. Oxford: Academic Press; 2014. p. 904-7. Available from: https://www. sciencedirect.com/science/article/ pii/B9780123851574004917

15. Vargas G, Gonzalez B, Ramirez C, Ferreira A, Espinosa E, Mendoza V, et al. Clinical characteristics and treatment outcome of 485 patients with nonfunctioning pituitary macroadenomas. Int J Endocrinol 2015; 2015:756069.

https://doi.org/10.1155/2015/756069

16. Rehman L, Rehman UL, Jabeen R, Rizvi R. Endoscopic trans-sphenoidal surgery; efficacy and response in pituitary adenoma. Pakistan J Med 
Sci 2018; 34(2):412-7.

https://doi.org/10.12669/pjms.342.14002

17. Giustina A, Chanson P, Kleinberg D, Bronstein MD, Clemmons DR, Klibanski A, et al. Expert consensus document: A consensus on the medical treatment of acromegaly. Nat Rev Endocrinol 2014; 10(4):243-8. https://doi.org/10.1038/nrendo.2014.21

18. Gao Y, Zhong C, Wang Y, Xu S, Guo Y, Dai C, et al. Endoscopic versus microscopic transsphenoidal pituitary adenoma surgery: a metaanalysis. World J Surg Oncol 2014; 12(1):94.

https://doi.org/10.1186/1477-7819-12-94

19. D'Haens J, Van Rompaey K, Stadnik T, Haentjens P, Poppe K, Velkeniers B. Fully endoscopic transsphenoidal surgery for functioning pituitary adenomas. Surg Neurol 2009;
72(4):336-40.

h t tps://doi.org/10.1016/j. surneu.2009.04.012

20. Razak AA, Horridge M, Connolly DJ, Warren DJ, Mirza S, Muraleedharan $\mathrm{V}$, et al. Comparison of endoscopic and microscopic trans-sphenoidal pituitary surgery: early results in a single centre. Br J Neurosurg 2013; 27(1):40-3.

https://doi.org/10.3109/02688697.201 2.703353

21. Goudakos JK, Markou KD, Georgalas C. Endoscopic versus microscopic trans-sphenoidal pituitary surgery: a systematic review and metaanalysis. Clin Otolaryngol 2011; 36(3):212-20. https://doi.org/10.1111/j.17494486.2011.02331.x 